\title{
DESIGN OF METAL HEAT CONDUCTIVITY MEASUREMENT USING PROBE METHOD
}

\author{
Fitria Hidayanti*, Hari Hadi Santoso, Gigih Baskara \\ Engineering Physics Department, Universitas Nasional, Jakarta 12520, Indonesia \\ *Corresponding Author Email: fitriahidayanti@gmail.com
}

Received: 27 March 2020

Revised: 26 April 2020

Accepted: 26 April 2020

Online: 28 April 2020

Published: 30 April 2020

SPEKTRA: Jurnal Fisika dan Aplikasinya

p-ISSN: 2541-3384

e-ISSN: 2541-3392

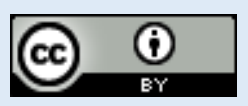

\begin{abstract}
This study aims to design a tool that can measure the heat conductivity of metals by the Probe method. The design method used a heatflowing metal beam and an LM35 temperature sensor to measure temperature changes on the probe. This measurement system design is based on conduction heat transfer; meanwhile, the metal used is aluminum and carbon steel. For each tested metal, an LM35 temperature sensor is placed on the metal to find out that a temperature change has occurred. The conductivity value can be obtained from the temperature difference between the probe and the metal being tested, the temperature change of the probe, the temperature change of the metal being tested, and the heating time. This value is processed and calculated by the microcontroller into the value of heat conductivity. The measurement results show that the average heat conductivity value is $214.93 \mathrm{~W} / \mathrm{m}^{\circ} \mathrm{C}$ for aluminum and $53.81 \mathrm{~W} / \mathrm{m}^{\circ} \mathrm{C}$ for carbon steel.
\end{abstract}

Keywords: heat conductivity, measurement, metal, probe, LM35 


\section{INTRODUCTION}

The thermal conductivity $[1,2]$ of material is essential for planning heat exchanger equipment in factories, power plants, and the machining world. The nature of heat conductivity plays a role in the process of heat transfer conduction of different magnitude for each material, so it will be easier to choose the material to be used in the design depending on its function for heating, cooling, or also for heat-insulating. From an engineering point of view, the main problem is determining the rate of heat transfer at the specified temperature difference. It's determined by the test using the equipment that can be easily used according to demands.

By testing the heat conductivity of materials, which is one of the important physical properties to show how quickly the heat that flows in a particular material, we can find out whether a material can be classified as a conductor or as an insulator. Materials that have a high value of heat conductivity can be used as a conductor [3], and vice versa is used as an insulator. Therefore, it is necessary to design and measure the heat conductivity of materials and tests them.

The conductivity meter [4] is very needed in the testing laboratory. The more industries that require the heat conductivity of the made product, the more often the industry asks the value of heat conductivity in the testing laboratory. In addition to the lab and industry, researchers, in particular, who want to research new materials to be used as insulators [5], or new alloys for metals, also require heat conductivity measuring devices that are practical and easy to make.

Measurement of heat conductivity is critical in several engineering applications. The properties of this material are used as a measure of the used material quality. Specialized laboratories for measuring heat conductivity are needed [6]. The direction of measurement is also important for heat conductivity measurement, which is higher in the axial direction [7]. The rate of heat flow in the axial direction in two and a half times higher than the other direction [8].

This probe method has been developed previously $[9,10]$. The measurement of heat conductivity was done using a probe rod from hot-flowing metal and a temperature sensor in the middle of the probe heater to determine the temperature changes of the probe. The measurement results were not presented, only presents the calibration results of measuring instruments that have been made. For this reason, this research will design a heat conductivity measurement tool and prove the accuracy of the heat conductivity measurement results on metals by the probe method.

\section{METHOD}

The device made in this study is using heat propagation principle, conduction. Heat flows because there is a temperature difference between two objects. The heat flows from high temperature to low temperature. The system monitoring is designed uses CodeVisionAVR $[11,12]$, which controls the traffic of this device system. CodeVisionAVR acts as a program 
that instructs the system to work. CodeVisionAVR is then stored in Atmega8L. This device is equipped with various electronic components in carrying out the process on the system.

The used heat conductor in this tool is a conductor media. In principle, this tool serves to measure the value of metal conductivity. The using tool starts with heating the probe by a heater installed inside the probe until the probe is hot enough, according to a predetermined temperature, then, the probe can be affixed to the tested metal. The heat will transfer from the hotter probe to the cooler tested metals. So the tested metal at a specific time has a higher temperature than originally. The time required for the tested metal to reach a predetermined temperature will be calculated using a formula into the value of heat conductivity. The temperature sensor used is IC LM35 [13]. This sensor reads the initial temperature of the tested metal before it is heated. The sensor also reads the temperature of the heated probe and ensures that heat has been spread evenly across the probe so that the measurement can be started by measuring the temperature between the probe and the tested metal. The results of temperature and time measurements will be processed and calculated by the Atmega8L microcontroller [14], then the result, the heat conductivity, is displayed by the LCD. FIGURE 1 shows the design of heat conductivity measuring devices in the block diagram.

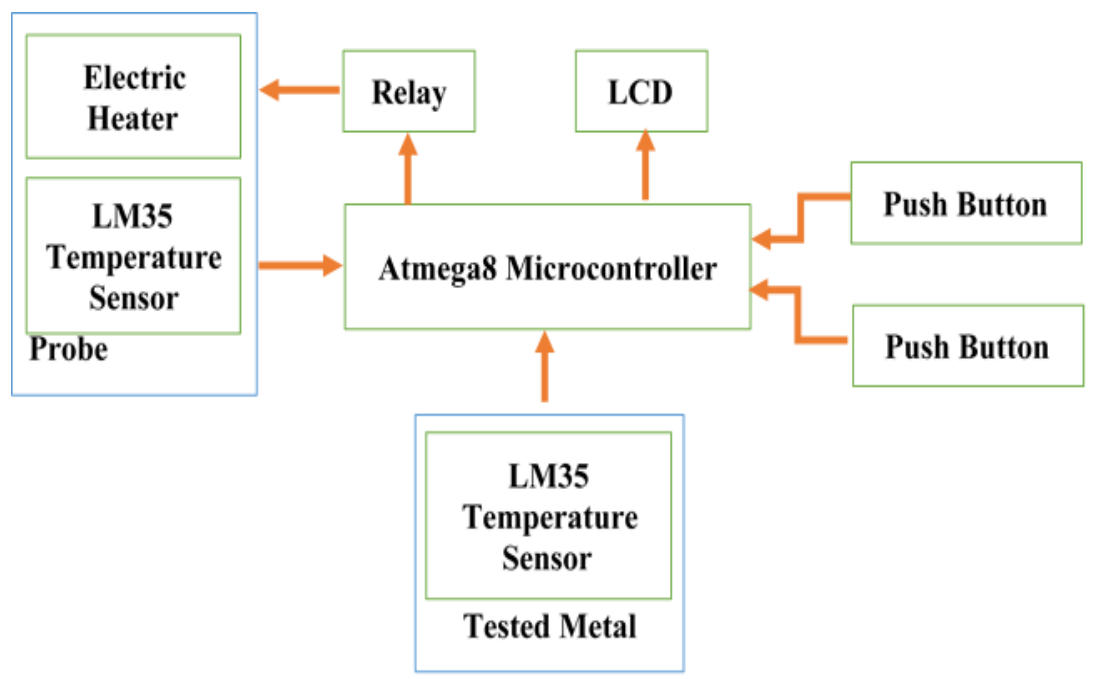

FIGURE 1. The diagram of a metal heat conductivity measuring instrument.

The flow chart for measuring heat conductivity is described in FIGURE 2. The circuit consists of several parts; there are power supplies, microcontroller (reset and interface to PC), input (LM35 temperature sensor three pieces, and two pushbuttons), and output (heater and LCD). The workings of heat conductivity measuring devices in this study can be seen in the flow chart in FIGURE 2. 


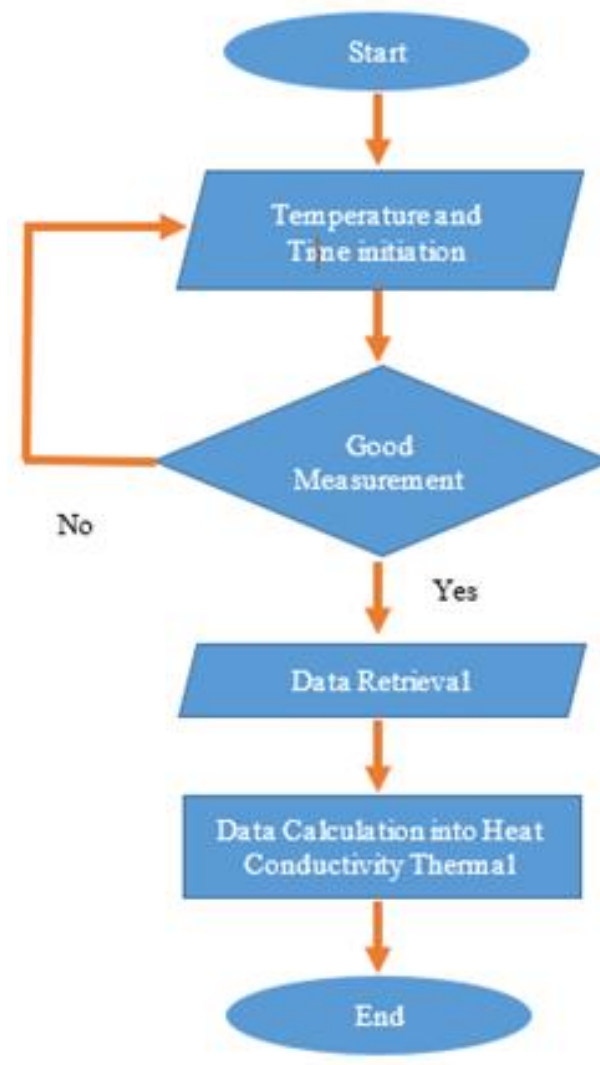

FIGURE 2. Diagram of a metal heat conductivity measuring instrument

\section{RESULT AND DISCUSSION}

Measurements were made to determine the value of heat conductivity in metals. The metals used as the test sample are aluminum and carbon steel, meanwhile, the probe uses copper with a content $>99.9 \%$ of $\mathrm{Cu}$. The probe is beam-shaped and has a mass of $0.236 \mathrm{~kg}$, a $80 \mathrm{~mm}$ length, a $19 \mathrm{~mm}$ width, and a thickness of $20 \mathrm{~mm}$. The heater that used as the probe is given a voltage of $12 \mathrm{~V}$ and a current of $2 \mathrm{~A}$. The experiment results are presented in TABLE 3 to TABLE 6. The equation used to determine the value of heat conductivity is presented in EQUATION (1).

$$
K=\frac{L 2}{A 2} * \frac{1}{\left[\frac{\Delta T}{\left(24+\frac{92.04 * \Delta T 1}{t}+\frac{m 2 * c 2 * \Delta T 2}{t}\right)}-0.032\right]}
$$

where:

$\mathrm{K}=$ the heat conductivity of the metal being tested $\left(\mathrm{W} / \mathrm{m}^{\circ} \mathrm{C}\right)$

$\mathrm{L} 2=$ the tested metal thickness (m)

A2 = the cross-sectional area of the metal being tested (m)

$\Delta \mathrm{T}=$ the difference in temperature of the probe with the metal being tested $\left({ }^{\circ} \mathrm{C}\right)$ 
$\Delta \mathrm{T} 1=$ the different temperature of the probe, before and after heating $\left({ }^{\circ} \mathrm{C}\right)$

$\Delta \mathrm{T} 2=$ the temperature difference of the tested metal, before and after it is heated $\left({ }^{\circ} \mathrm{C}\right)$

$\mathrm{t}=$ the heating time $(\mathrm{s})$

$\mathrm{m} 2=$ the mass of the metal being tested $(\mathrm{kg})$

$\mathrm{c} 2=$ the specific metal heats tested $\left(\mathrm{J} / \mathrm{kg} .{ }^{\circ} \mathrm{C}\right)$

TABLE 1. The dimensions and mass of tested metal.

\begin{tabular}{llll}
\hline Metal & $\begin{array}{l}\text { Thickness } \\
(\mathbf{m m})\end{array}$ & $\begin{array}{l}\text { Cross-sectional area } \\
\left(\mathbf{m m}^{2}\right)\end{array}$ & Mass $(\mathbf{k g})$ \\
\hline Aluminum 1 & 15.5 & 1600 & 0.062 \\
Aluminum 2 & 19.0 & 1520 & 0.074 \\
Carbon Steel 1 & 10.0 & 1560 & 0.112 \\
Carbon Steel 2 & 19.0 & 1520 & 0.232 \\
\hline
\end{tabular}

TABLE 2. The specific heat of the tested metal.

\begin{tabular}{ll}
\hline Metal & $\mathbf{c}\left(\mathbf{J} / \mathbf{k g .}{ }^{\circ} \mathbf{C}\right)$ \\
\hline Copper & 390 \\
Aluminum & 910 \\
Carbon Steel & 490 \\
\hline
\end{tabular}

TABLE 3. The heat conductivity measurement results on aluminum with a thickness of $15.5 \mathrm{~mm}$.

\begin{tabular}{llllll}
\hline Testing & $\mathbf{t}(\mathbf{s})$ & $\boldsymbol{\Delta} \mathbf{T}_{\mathbf{1}}\left({ }^{\mathbf{O}} \mathbf{C}\right)$ & $\Delta \mathbf{T}_{\mathbf{2}}\left({ }^{\mathbf{}} \mathbf{C}\right)$ & $\Delta \mathbf{T}\left({ }^{\mathbf{o}} \mathbf{C}\right)$ & $\mathbf{K}\left(\mathbf{W} / \mathbf{m}^{\mathbf{0}} \mathbf{C}\right)$ \\
\hline 1 & 345 & 27 & 21 & 3 & 177.39 \\
2 & 313 & 24 & 18 & 3 & 174.68 \\
3 & 312 & 24 & 17 & 3 & 173.50 \\
4 & 354 & 27 & 22 & 3 & 176.49 \\
5 & 324 & 25 & 18 & 3 & 174.15 \\
6 & 327 & 25 & 18 & 3 & 173.40 \\
7 & 311 & 24 & 18 & 3 & 175.21 \\
8 & 333 & 26 & 19 & 3 & 175.51 \\
9 & 316 & 24 & 18 & 3 & 173.90 \\
10 & 322 & 26 & 19 & 3 & 178.39 \\
\hline
\end{tabular}

The heat conductivity measurement results of aluminum were presented in TABLE 3 and TABLE 4. The average heat conductivity value of aluminum with a thickness of $15.5 \mathrm{~mm}$ is 175.26 W/m ${ }^{\circ} \mathrm{C}$, and the average heat conductivity value of aluminum with a thickness of 19 
$\mathrm{mm}$ is $214.93 \mathrm{~W} / \mathrm{m}^{\circ} \mathrm{C}$. The aluminum of 15.5 thickness $\mathrm{mm}$ and $19 \mathrm{~mm}$, do not come from the same aluminum, so the contents of the two aluminum are different, and cause the value of heat conductivity is different, as shown in FIGURE 3. The average heat conductivity value of aluminum, both size samples, are smaller than the reference. The error value of measuring aluminum with a thickness of $15.5 \mathrm{~mm}$ is $14.51 \%$, and the error value of measuring aluminum with a thickness of $19 \mathrm{~mm}$ is $4.84 \%$. These errors occur because the aluminum used in measurement is an aluminum alloy from several metals.

TABLE 4. The heat conductivity measurement results on aluminum with a thickness of $19 \mathrm{~mm}$.

\begin{tabular}{llllll}
\hline Testing & $\mathbf{t}(\mathbf{s})$ & $\Delta \mathbf{T}_{\mathbf{1}}\left({ }^{\mathbf{0}} \mathbf{C}\right)$ & $\Delta \mathbf{T}_{\mathbf{2}}\left({ }^{\mathbf{0}} \mathbf{C}\right)$ & $\Delta \mathbf{T}\left({ }^{\mathbf{0}} \mathbf{C}\right)$ & $\mathbf{K}\left(\mathbf{W} / \mathbf{m}^{\mathbf{0}} \mathbf{C}\right)$ \\
\hline 1 & 266 & 18 & 11 & 3 & 212.32 \\
2 & 282 & 18 & 13 & 3 & 211.99 \\
3 & 284 & 17 & 12 & 3 & 205.86 \\
4 & 280 & 20 & 16 & 3 & 226.64 \\
5 & 237 & 14 & 9 & 3 & 202.37 \\
6 & 292 & 20 & 13 & 3 & 215.20 \\
7 & 281 & 18 & 16 & 3 & 219.52 \\
8 & 309 & 23 & 17 & 3 & 228.37 \\
9 & 257 & 16 & 11 & 3 & 208.37 \\
10 & 304 & 21 & 15 & 3 & 219.02 \\
\hline
\end{tabular}

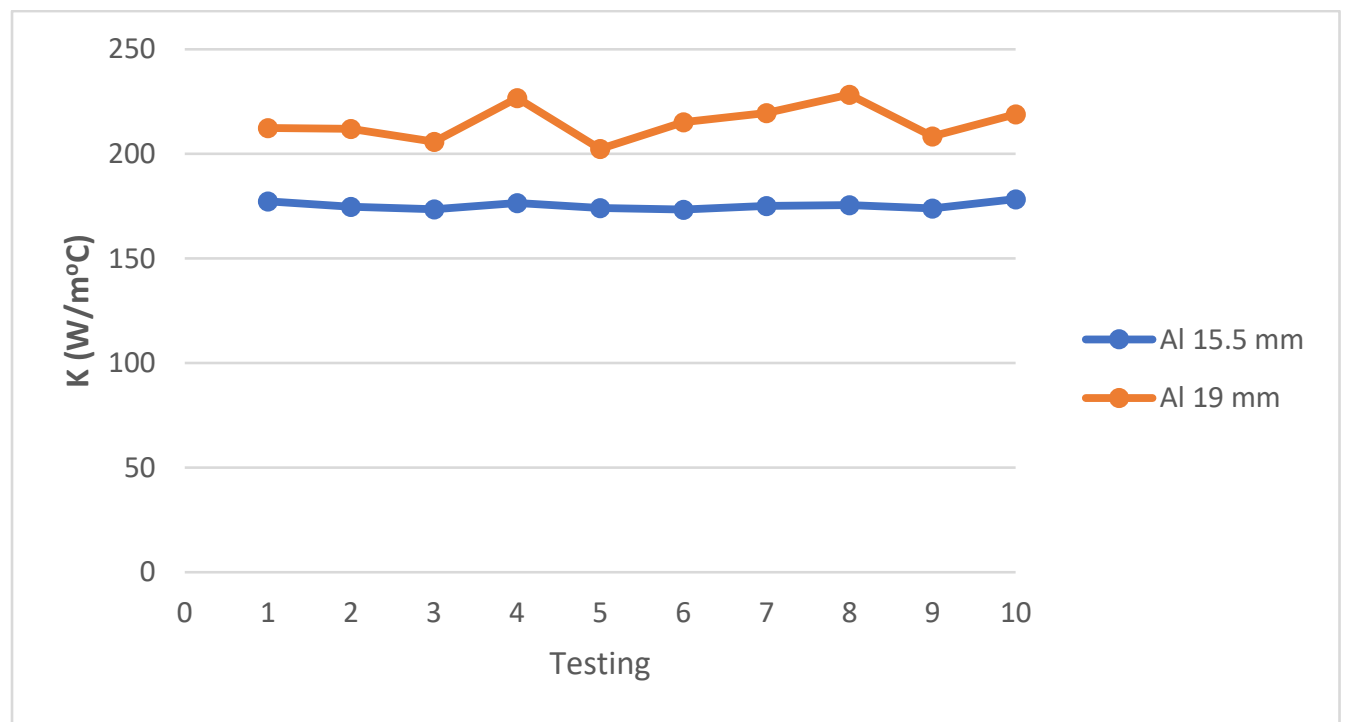

FIGURE 3. The heat conductivity of aluminum. 
For the heat conductivity value to be more accurate, the temperature sensor used must have a higher-resolution value.

TABLE 5. The heat conductivity measurement results on carbon steel with a thickness of $10 \mathrm{~mm}$.

\begin{tabular}{llllll}
\hline Testing & $\mathbf{t}(\mathbf{s})$ & $\Delta \mathbf{T}_{\mathbf{1}}\left({ }^{\mathbf{0}} \mathbf{C}\right)$ & $\Delta \mathbf{T}_{\mathbf{2}}\left({ }^{\mathbf{0}} \mathbf{C}\right)$ & $\Delta \mathbf{T}\left({ }^{\mathbf{0}} \mathbf{C}\right)$ & $\mathbf{K}\left(\mathbf{W} / \mathbf{m}^{\mathbf{0}} \mathbf{C}\right)$ \\
\hline 1 & 254 & 20 & 12 & 5 & 55.38 \\
2 & 239 & 18 & 12 & 5 & 55.06 \\
3 & 212 & 15 & 9 & 5 & 53.31 \\
4 & 219 & 16 & 9 & 5 & 53.59 \\
5 & 255 & 21 & 10 & 5 & 55.15 \\
6 & 290 & 21 & 10 & 5 & 53.50 \\
7 & 263 & 19 & 10 & 5 & 53.09 \\
8 & 250 & 18 & 10 & 5 & 53.27 \\
9 & 248 & 16 & 10 & 5 & 51.90 \\
10 & 259 & 19 & 11 & 5 & 53.81 \\
\hline
\end{tabular}

TABLE 6. The heat conductivity measurement results on carbon steel with a thickness of $19 \mathrm{~mm}$.

\begin{tabular}{llllll}
\hline Testing & $\mathbf{t}(\mathbf{s})$ & $\Delta \mathbf{T}_{\mathbf{1}}\left({ }^{\mathbf{0}} \mathbf{C}\right)$ & $\boldsymbol{\Delta}_{\mathbf{2}}\left({ }^{\mathbf{0}} \mathbf{C}\right)$ & $\Delta \mathbf{T}\left({ }^{\mathbf{0}} \mathbf{C}\right)$ & $\mathbf{K}\left(\mathbf{W} / \mathbf{m}^{\mathbf{0}} \mathbf{C}\right)$ \\
\hline 1 & 541 & 26 & 15 & 9 & 49.40 \\
2 & 578 & 26 & 18 & 9 & 49.59 \\
3 & 561 & 26 & 16 & 9 & 49.28 \\
4 & 461 & 23 & 14 & 9 & 50.23 \\
5 & 485 & 22 & 16 & 9 & 50.02 \\
6 & 533 & 27 & 18 & 9 & 51.04 \\
7 & 466 & 22 & 13 & 9 & 49.30 \\
8 & 532 & 20 & 14 & 9 & 47.43 \\
9 & 459 & 21 & 15 & 9 & 50.02 \\
10 & 234 & 16 & 5 & 9 & 51.43 \\
\hline
\end{tabular}

TABLE 5 and TABLE 6 show the results of measurement on carbon steel. The average heat conductivity value of carbon steel with a thickness of $10 \mathrm{~mm}$ is $53.81 \mathrm{~W} / \mathrm{m}^{\circ} \mathrm{C}$, and the average heat conductivity value of carbon steel with a thickness of $19 \mathrm{~mm}$ is $49.77 \mathrm{~W} / \mathrm{m}^{\circ} \mathrm{C}$. The error value of the carbon steel measurement with a thickness of $10 \mathrm{~mm}$ and $19 \mathrm{~mm}$ is $0.36 \%$ and $7.83 \%$, respectively. The LM35 temperature sensor readings are unstable and inaccurate. This 
is due to the rust on carbon steel $19 \mathrm{~mm}$, which causes the value of heat conductivity on carbon steel $19 \mathrm{~mm}$ to fall.

\section{CONCLUSION}

In this research, the design of heat conductivity measurement using a probe method has been carried out. The probe used is in the form of blocks and is made of copper (content $>99.9 \%$ $\mathrm{Cu}$ ). Metals used as testing materials are aluminum with two kinds of thickness and carbon steel with two kinds of thickness. The developed tool was able to show differences in the heat conductivity measurement results of the two different metals. Errors or inaccuracies of the measurements occur because this probing method requires a very flat cross-section of the probe and tested material. If it is not entirely flat, there will be a cavity that causes entering air, so the conduction process is not perfect, and it takes quite a long time for heat to move from the probe to the tested metal.

\section{REFERENCES}

[1] S. Wu et al., "Thermal conductivity enhancement on phase change materials for thermal energy storage: A review," Energy Storage Materials, 2019.

[2] S. I. S. de Souza et al., "Numerical investigation of convection in tubes with aluminium and carbon steel fins: evaluating the assumption of convective heat transfer coefficient as that for the tube without fins and relating physical processes with the optimum spacing between fins," Journal of the Brazilian Society of Mechanical Sciences and Engineering, 2019.

[3] L. Wang, et al., "Electromagnetic interference shielding MWCNT-Fe3O4@ Ag/epoxy nanocomposites with satisfactory thermal conductivity and high thermal stability," Carbon, 2019.

[4] G. Baldinelli, et al., "Thermal conductivity measurement of insulating innovative building materials by hot plate and heat flow meter devices: A Round Robin Test," International Journal of Thermal Sciences, 2019.

[5] H. Ao et al., "Accelerated lifetime test of vibration isolator made of Metal Rubber material,” IOP Conference Series: Materials Science and Engineering, 2017.

[6] W. Adamczyk et al., "CFD estimation of heat losses in thermal conductivity measurements," Computer Assisted Methods in Engineering and Science, 2017.

[7] O.S. Samuel et al., "Thermal conductivity of three different wood products of Combretaceae family; Terminalia superb, Terminalia ivorensis and Quisqualis indica," Journal of Natural Sciences Research, 2012.

[8] N. J. Kotlarewski et al., "Thermal conductivity of Papua New Guinea balsa wood measured using the needle probe procedure," BioResources, 2014.

[9] K. Manohar et al., "Measurement of apparent thermal conductivity by the thermal probe method," Journal of Testing and Evaluation, 2000. 
[10] S. Goodhew and R. Griffiths, "Analysis of thermal-probe measurements using an iterative method to give sample conductivity and diffusivity data," Applied Energy, 2004.

[11] A. Dragomir et al., "Temperature logger for Electrical Equipment's Thermal Stress Monitoring. in 2019 8th International Conference on Modern Power Systems (MPS)," IEEE, 2019.

[12] F. Shirmohammadi and A. Tohidi, "Experimental and Numerical Analysis of Chaotic Advection as An Efficient Approach to Maximize Homogeneous Laminar Mixing in A Batch Mixer,” Brazilian Journal of Chemical Engineering, 2019.

[13] E. H. Goud et al., "Real Time Based Temperature Control Using Arduino," International Journal of Innovations in Engineering and Technology, 2017.

[14] F. H. Danufane et al., "Design of Automated PC Shutdown Control System in Coastal/LPI Radar System Based on Microcontroller ATMega8L," Jurnal Elektronika dan Telekomunikasi, 2016. 
